\title{
Aortic root dissection
}

Sir,

Candell-Riera and co-workers recently reported early systolic closure of the aortic valve in two cases with aortic root dissection. ${ }^{1}$ They state that this partial closure of the aortic valve has also been observed in discrete subaortic stenosis, mitral regurgitation, and ventricular septal defect.

Apart from these conditions, partial closure of the aortic valve has been shown in hypertrophic cardiomyopathy with and without obstruction ${ }^{2}$ and in ruptured right coronary sinus of Valsalva aneurysm into the right ventricle. ${ }^{3}$ The haemodynamic situation in the latter condition may be similar to that in case 1 of the report by Candell-Riera and his colleagues in which the aortic root dissection ruptured into the pericardial and pleural spaces.

In the echocardiogram of this case (Fig. 1B) a structure is identified by a lower, large horizontal arrow, as the external layer of the aorta. The motion of this structure, however, appears to be out of phase with that of the anterior aortic root. The patient had a pericardial effusion and I wonder whether it is the left atrial wall which is labelled and the echo-free space posterior is a pericardial effusion behind the left atrium. ${ }^{4} \mathrm{~A}$ continuous sweep recording from the aortic root through the mitral valve to the left ventricular plane might have clarified the situation.

Yoshinori L Doi,
The Third Division (Cardiology),
Department of Medicine,
Osaka Medical College,
Takatsuki-city,
Osaka 569,
Japan.

\section{References}

1 Candell-Riera J, Garcia del Castillo H, Rius J. Aortic root dissection. Another cause of early systolic closure of the aortic valve. $B r$ Heart $f$ 1980: 43: 579-81.

2 Doi YL, McKenna WJ, Gehrke J, Oakley CM, Goodwin JF. M-mode echocardiography in hypertrophic cardiomyopathy: diagnostic criteria and prediction of obstruction. Am f Cardiol 1980; 45: 6-14.

3 Johnson ML, Warren SG, Waugh RA, Kisslo JA, Sabiston DC, Lester RG. Echocardiography of the aortic valve in non-rheumatic left ventricular outflow tract lesions. Radiology 1974; 112: 677-84.
4 Greene DA, Kleid JJ, Naidu S. Unusual echocardiographic manifestation of pericardial effusion. $A m \mathcal{F}$ Cardiol 1977; 39: 112-5.

This letter was shown to Dr Candell-Riera who replies as follows:

Sir,

In our two reported cases of aortic root dissection as well as in a more recent one that we have had the opportunity of seeing, the partial systolic aortic closure recorded in the echocardiogram was very premature (less than $0.05 \mathrm{~s}$ from the opening point). For that reason we did not discuss the differential diagnosis with hypertrophic cardiomyopathy, since in the latter condition the closure of the aortic leaflets occurs later (at $0 \cdot 14 \pm 0.04 \mathrm{~s}$ from the opening point) as Krajcer et al. ${ }^{1}$ have shown. Accordingly, Doi et al. ${ }^{2}$ have referred to this closure in the obstructive and non-obstructive hypertrophic cardiomyopathy as being "midsystolic" rather than "early systolic".

We agree with Dr Doi that this early systolic closure of the aortic leaflets can be seen in a ruptured right coronary sinus of Valsalva into the right ventricle and have recently seen such a case. We have also observed this sign in a case of constrictive pericarditis, in aortic regurgitation with severe aortic root dilatation without dissection, and in situations of severe low cardiac output. Moreover, Krueger et al. ${ }^{3}$ have pointed out the presence of a slight systolic aortic partial closure in normal subjects.

As we mention in our paper, pericardial effusion posterior to the left atrium can be confused with dissection of the posterior wall of the aorta. This possibility, which Dr Doi refers to in relation to Fig. 1B of our report, can be ruled out, not only by the continuous sweep recording from the aortic root to the left ventricle, but also by aortography. In the left lateral projection of the angiogram the false lumen of the aorta was seen in the anterior as well as in the posterior wall, thus coinciding with the echocardiographic recordings of the false lumen in size and location.

J Candell-Riera,

Unidad Coronaria,

Ciudad Sanitaria de la Seguridad Social, Barcelona, Spain. 


\section{References}

1 Krajcer Z, Orzan F, Pechacek LW, García E, Leachman RD. Early systolic closure of the aortic valve in patients with hypertrophic subaortic stenosis and discrete subaortic stenosis. Correlation with preoperative and postoperative hemodynamics. $\mathrm{Am} \mathcal{F}$ Cardiol 1978; 41: 823-9.
2 Doi YL, McKenna WJ, Gehrke J, Oakley CM, Goodwin JF. M-mode echocardiography in hypertrophic cardiomyopathy: diagnostic criteria and prediction of obstruction. Am f Cardiol 1980; 45: 6-14.

3 Krueger SK, French JW, Forker AD, Caudill CC, Popp RL. Echocardiography in discrete subaortic stenosis. Circulation 1979; 59: 506-13. 